\title{
Challenges and Limitations in the Diagnosis of Atrio-Esophageal Fistula
}

Franeis J. Ha MBBS BMedSc ${ }^{1}$, Hui-Chen Han MBBS BMedSc ${ }^{1,2}$, Prashanthan Sanders MBBS PhD ${ }^{3}$, Andrew W. Teh MBBS $\mathrm{PhD}^{1,2}$, David O'Donnell MBBS ${ }^{1}$, Omar Farouque MBBS $\mathrm{PhD}^{1,2}$, Han S. Lim MBBS PhD ${ }^{1,2,4}$

1. Austin Health, Melbourne, Victoria, Australia.

2. University of Melbourne, Melbourne, Victoria, Australia.

3. Centre for Heart Rhythm Disorders (CHRD), South Australia Health and Medical Research Institute (SAHMRI), University of Adelaide and Royal Adelaide Hospital, South Australia, Australia.

4. Northern Health, Melbourne, Victoria, Australia.

Running title: Investigations for suspected AEF after AF ablation

\section{Corresponding author:}

Dr Han S. Lim

Department of Cardiology, Austin Hospital

Level 5N, 145 Studley Road, Heidelberg 3084, Victoria, Australia

Telephone: +61394965000

Facsimile: 61394590971

Email: lim.h@unimelb.edu.au

Disclosures: None

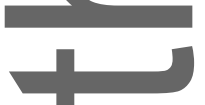

ABSTRACT

Introduction: Atrio-esophageal fistula (AEF) is a dire complication of atrial fibrillation ablation. The diagnostic yield of computed tomography (CT) chest, the role and timing of repeat testing, and the value of other investigations in the diagnosis of AEF is uncertain.

This is the author manuscript accepted for publication and has undergone full peer review but has not been through the copyediting, typesetting, pagination and proofreading process, which may lead to differences between this version and the Version of Record. Please cite this article as doi:

10.1111/jce.13494.

This article is protected by copyright. All rights reserved. 
Methods: We systematically reviewed published AEF cases to evaluate radiological, bedside and biochemical investigations for AEF (registered on PROSPERO [CRD42017077493]).

Results: Eighty-seven articles with 126 patients (median age, 59 years; male, 71\%) were included in the analysis. CT chest was performed in $88 \%(111 / 126)$ and was abnormal in 87\%. A clear diagnosis of AEF (fistula/perforation) was only detected in $35 \%$ (34/97). Other major findings included free air in mediastinum (26\%), left atrium (LA) or LA wall (24\%). In 11 patients with normal/non-specific initial CT chest, major abnormalities were detected in 91\% (10/11) of repeat CT chest performed 6 days (median; range, 4-22) after initial scan. Initial CT head was normal in 51\%; diffuse air emboli was identified in 79\% (22/28). Initial trans-thoracic echocardiography was normal in $61 \%$ of cases. The spectrum of radiological abnormalities Included Air (mediastinum/LA), Effusion (pleural/pericardial), Fistula/Perforation, and Thickening (esophagus/LA) - “AEF-Tests". Esophagram demonstrated contrast extravasation in $87 \%(13 / 15)$. Blood culture was consistently positive $(100 \% ; 28 / 28)$, particularly for streptococcus species $(93 \% ; 26 / 28)$.

Conclusion: The diagnosis of AEF remains challenging. Clinicians should be aware of the limitations in the yield of CT chest, the variety of major abnormalities reported, the need for repeat testing, unique brain imaging findings, and the importance of positive blood cultures and raised inflammatory markers.

Keywords: atrio-esophageal fistula, investigations, computed tomography, atrial fibrillation, complications, catheter ablation, safety

\section{INTRODUCTION}

The prevalence and burden of atrial fibrillation (AF) is increasing globally. ${ }^{1,2}$ Similarly, catheter ablation has become more frequently performed for the treatment of $\mathrm{AF}^{3}$ and is regarded as a relatively safe procedure associated with marked symptomatic improvement. ${ }^{4,5}$ However, it still carries a risk of major complications as reported in up to $5 \%$ of cases. ${ }^{6,7}$ Atrio-esophageal fistula (AEF) is one of the most dire complications and, while rare, ${ }^{8}$ is associated with significant mortality without early detection and appropriate management. ${ }^{9}$ 
Computed tomography (CT) of the chest is often considered the best diagnostic modality for AEF. ${ }^{10}$ However, the presence of obvious perforation or fistula may be a late sign, and the yield of even detecting this specific salient abnormality depending on when the investigation is carried out remains uncertain. Moreover, there is currently no consensus on how clinicians should manage patients who are symptomatic (e.g., chest pain, dyspnoea, fever) but who have relatively non-specific findings on $\mathrm{CT}$ chest. In this context, the role and timing of repeat $\mathrm{CT}$ chest, other imaging modalities that may corroborate findings, as well as blood tests needs to be ascertained to minimize the risk of patients being prematurely discharged with likely rehospitalization and significantly poorer prognosis by that stage.

We have previously reported on the clinical presentation, diagnosis and outcomes of patients with AEF. ${ }^{11}$ In this systematic review, we aimed to further elucidate the yield, specific findings and utility of various radiological, bedside and biochemical investigations in diagnosing AEF, including the role of repeat testing for CT chest.

\section{METHODS}

\section{Data sources and search strategy}

A digital literature search was performed through the PubMed and EMBASE databases up to 5 November 2017. Keywords using Medical Subject Heading (MeSH) where available, included 'atrial fibrillation, 'esophageal fistula', 'complications' and 'catheter ablation'. Titles and abstracts were screened for relevance and reference lists of eligible articles were also screened for further potential citations. The study protocol was prospectively registered with the PROSPERO international register (CRD42017077493).

\section{Study selection}


Study characteristics for inclusion were as follows: (1) case reports, case series or prospective studies reporting cases of AEF, (2) patient underwent surgical or percutaneous catheter ablation for $\mathrm{AF}$, (3) development of $\mathrm{AEF}$ following ablation procedure, (4) documented investigations performed, (5) English language, and (6) fully published status. We excluded studies published only in abstract form and articles that did not report on investigations that lead to the diagnosis of AEF. All cases must have had confirmed AEF or variant (e.g., pericardio-esophageal fistula) either through relevant imaging modality, peri-operatively or on autopsy.

\section{Data extraction and synthesis}

Data items to be collected were specified prior to the literature search. Two investigators (FJH and $\mathrm{HH}$ ) independently conducted the literature search and performed data extraction for study design, baseline characteristics, investigations performed and their findings. Extracted data were verified by the senior author (HL), with any discrepancies resolved by consensus. The main imaging modalities evaluated were computed tomography (CT) of the chest, CT and magnetic resonance imaging (MRI) head, trans-thoracic (TTE) and transesophageal (TEE) echocardiography. Other radiological investigations included esophagram, $\mathrm{CT}$ of the abdomen/pelvis and chest x-ray. Bedside, blood and biochemical investigations collected included electrocardiogram (ECG), inflammatory markers including white cell count (WCC), c-reactive protein (CRP) and troponin assays, blood culture and lumbar puncture. Where reported, specific values of inflammatory markers were obtained and presented as a median with relevant ranges.

\section{RESULTS}

A total of 648 citations were reviewed and screened, with 428 studies identified for potential inclusion and further evaluation. Excluded articles did not have documented AEF or lacked This article is protected by copyright. All rights reserved. 
relevant specific case information $(n=94)$, were conference meeting abstracts $(n=92)$, were not in English language $(\mathrm{n}=17)$, or did not provide information about radiological investigations $(n=5)$ (Table S1 in the Data Supplement). Eighty-seven articles with a total of 126 patients were included in final analysis (Table S2 in the Data Supplement). The search algorithm and other reasons for study exclusion are provided in the PRISMA study flowchart (Figure 1).

\section{Baseline Characteristics}

The median age was 59 years (range, 27-85 years) and most patients were male (71\%) (Table 1). Where reported, there were similar proportions of patients with paroxysmal or persistent (36/126) AF. Most reported cases followed percutaneous radiofrequency ablation (99/126; 79\%) with 18/126 (14\%) following surgical ablation. There were 8 cases $(6 \%)$ following cryoballoon ablation and 1 case following high-intensity focused ultrasound ablation. The most common radiological investigations performed for initial evaluation of suspected AEF was CT chest (111/126; 88\%), followed by CT head (55/126; 44\%) and TTE (36/126; 29\%) (Figure 2). The most common method of diagnosis was CT chest (Figure 3).

\section{CT Chest}

In 111 patients who underwent $\mathrm{CT}$ chest, most patients demonstrated abnormal findings on initial scan $(97 / 111 ; 87 \%)$ performed a median of 21 days (range, 1-66 days) after ablation procedure However, CT chest was normal even up to 42 days post-ablation (Figure S1, Data Supplement). Additionally, a clear AEF diagnosis, recognized as either fistulous tract or esophageal perforation, was only detected in 35\% (34/97) of initial CT chest. Instead, other abnormalities included free air in the mediastinum $(25 / 97 ; 26 \%)$, in the left atrium (LA) or wall of the LA (23/97; 24\%). Further details of abnormal findings on initial CT chest are 
summarized in Figure 4. Where the use of contrast was specified (92/111), most CT chest scans were performed with intravenous and/or oral contrast $(83 / 92 ; 90 \%)$. Figure 5 depicts case examples of chest CT findings including pneumomediastinum, pneumopericardium, hemopericardium and LA air.

\section{Normal Initial CT Chest}

Fourteen patients $(13 \%)$ demonstrated normal or non-specific findings on initial CT chest which was performed a median of 14 days (range, 3-28 days) after AF ablation. The most common presenting symptoms reported were fever $(64 \% ; 9 / 14)$, chest pain $(43 \% ; 6 / 14)$ and chills/rigors (36\%; 5/14) (Table S3 in the Data Supplement). In 7 patients whose blood culture results were reported at the time of initial CT chest, all grew streptococcus species with most (5/7) growing multiple organisms including gemella morbillorum, lactobacillus, candida albicans, enterococcus faecalis and streptococcus viridians. ${ }^{12-16}$ In 5 patients who had biochemistry results reported, 2 were normal. In the other 3 patients, 2 had an elevated WCC (up to $18,000 / \mu \mathrm{L}$ in 1 patient), 2 had an elevated CRP (100 and $116 \mathrm{mg} / \mathrm{dL}$, respectively) and 1 patient had an elevated procalcitonin. When reported, ECG was normal with non-specific $t$ wave changes in 1 patient, an ECG appearance of pericarditis in 2 patients, and ST-elevation in the inferior leads of 1 patient leading to coronary angiography (which was normal). In 3 patients who underwent CT head, all demonstrated normal findings. Similarly, in 5 patients who underwent echocardiography, all demonstrated normal findings. One of these patients underwent TEE and within a few hours had become aphasic with left-sided weakness. ${ }^{13}$ Esophagram was performed in 2 patients around the time of initial CT chest, and both were normal

\section{Repeat CT Chest}


Eleven patients whose initial CT chest, performed a median of 12 days (range, 3-28 days) post-procedure, was normal or showed non-specific findings underwent repeat CT chest investigation (Table 2). The repeat scan was usually performed (10/11) because the patient re-presented to the hospital with symptom recurrence or progression (e.g., new neurological event or chest pain). Only in 1 patient without further symptoms was the CT chest repeated because of the treating team's strong clinical suspicion based on the patient's original presentation. Repeat CT chest scan was abnormal in 10/11 patients, which was performed a median of 6 days (range, 4-22) after initial CT chest. Esophageal perforation or fistulous tract development was visualized in 4 cases and air in the mediastinum, pericardium, left atrium or left inferior pulmonary vein described in 7 studies (Figure 6).

\section{CT and MRI Head}

In 55 patients who underwent CT head, only one-half $(28 / 55 ; 51 \%)$ demonstrated an abnormality on initial scan (Figure 2). This was most commonly diffuse air emboli or ischemia $(22 / 28 ; 79 \%)$ followed by focal air emboli or ischemia $(5 / 28 ; 18 \%)$ particularly in the frontal lobe $(4 / 28 ; 14 \%)$. Case examples of diffuse air emboli, as well as intracranial hemorrhage are depicted in Figure 7. In contrast, most MRI head scans demonstrated abnormal findings on initial test (87\%) although was only reported/performed in 23 patients. Once again, diffuse air emboli and ischemia was the most frequent abnormal finding (14/20; 70\%). Further details of CT and MRI head findings are summarized in Figure S2 in the Data Supplement.

\section{Echocardiography}

In 36 patients who underwent TTE, only $39 \%$ (14/36) showed an initial abnormality (Figure 2). This included pericardial effusion (7/14; 50\%), LA thrombus $(3 / 14 ; 21 \%)$, air in the LA $(2 / 14 ; 14 \%)$ and wall akinesia $(2 / 14 ; 14 \%)$. Of note, 1 of the 2 patients with wall 
akinesia on TTE presented in the context of ST-elevation myocardial infarction detected on ECG. Fewer patients underwent TEE $(n=25)$ with abnormalities detected in $60 \%(15 / 25)$. Thrombus or non-specified mass in LA $(13 / 15 ; 87 \%)$ was the most common finding with locations including posterior LA wall (3/5), left inferior pulmonary vein (1/5) or intraluminal (1/5) where specified (5 cases). Other findings included air in LA $(1 / 15 ; 7 \%)$ or pericardial effusion $(1 / 15 ; 7 \%)$. Further details of TTE and TEE findings are described in Figure $\mathbf{S 3}$ in the Data Supplement.

\section{Other Imaging Modalities}

Other imaging modalities included MRI chest, CT abdomen/pelvis, esophagram and chest xray. Two MRI chest were reported across the included studies with 1 diagnosing AEF and another detecting an infected thrombus in the LA. CT abdomen/pelvis was performed in 5 patients, with multiple emboli in the liver, spleen and kidney described in 4 studies, while one (n)

study described normal findings. Esophagram was performed in 15 patients with 13 (87\%) demonstrating contrast extravasation. Chest x-ray in 13 patients mostly showed no abnormalities (7/13). In 6 chest x-rays that described abnormal findings, these included pleural effusion $(n=2)$, air in the pericardium $(n=1)$ or mediastinum $(n=1)$, non-specific lung infiltrates $(n=1)$ and pericardial effusion $(n=1)$.

\section{Bedside and Biochemical Tests}

In 23 ECGs performed and reported, 39\% were normal (9/23). ST-segment elevation was noted in 8 tests $(35 \%)$, supraventricular tachycardia in $3(13 \%)$, non-specific t-wave changes in $2(9 \%)$ and atrial fibrillation in $1(4 \%)$ ECG. Inflammatory markers were usually elevated when reported, including WCC $(72 \% ; 28 / 39)$, CRP $(93 \% ; 13 / 14)$ and troponin $(78 \% ; 7 / 9)$. Similarly, blood culture was consistently positive $(100 \% ; 28 / 28)$, with the most common species being streptococcus $(26 / 28 ; 93 \%)$, particularly $\alpha$-hemolytic streptococcus species This article is protected by copyright. All rights reserved. 
$(50 \% ; 14 / 28)$. Lumbar puncture was performed in 3 patients, with 1 result suggestive of meningitis, while no abnormalities were found in the other 2 lumbar punctures. Bedside, biochemical and blood tests details are summarized in Table S3 in the Data Supplement.

\section{DISCUSSION}

We performed a comprehensive systematic review of published AEF cases to determine the yield of diagnostic investigations and $\mathrm{CT}$ chest as the primary diagnostic modality, the role of repeat testing, and the utility of other relevant radiological, biochemical and bedside investigations to assist in forming an early diagnosis. The main findings are that

1) While contrast CT chest is the diagnostic modality of choice yielding an abnormal finding in $87 \%$ of initial scans, a clear diagnosis in the form of fistula or perforation is only seen in about one-third (35\%) of cases, performed at a median of 21 days (range 1-66 days). Air in the mediastinum or left atrium is otherwise observed in $50 \%$ of the

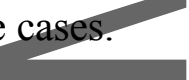

2) Approximately 1 in 10 patients (13\%) would have a normal initial CT chest. Repeat testing in the setting of strong clinical suspicion is critical, with $10 / 11$ yielding an abnormal result at a median of 6 days (range 4-22) from the initial CT chest.

3) The spectrum of abnormal findings detected on radiological tests such as CT and echocardiography include Air (in the mediastinum of LA), Effusion (either pleural or pericardial), Fistula or perforation, and Thickening (in the esophagus and LA wall), see

\section{Table 3}

4) CT head displays characteristic findings of diffuse air emboli and ischemia suggestive of AEF (79\% among abnormal findings), although may be normal in up to one-half of cases even in the presence of neurological symptoms 
5) MRI head, when performed, display similar findings to CT head although more frequently detected abnormalities

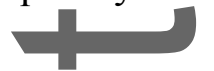

6) Positive blood cultures for bacterial growth and raised inflammatory markers are warning signs, even in patients with initially normal CT chest; and

7) Esophagram, while infrequently performed, demonstrated contrast extravasation in most patients $(87 \% ; 13 / 15)$.

\section{Major Abnormalities on CT Chest}

CT chest is widely considered the best diagnostic modality for detecting AEF. However, there are no published data regarding its actual diagnostic yield and the array of findings on initial scan in suspected AEF. In this study, we found that while CT chest yielded abnormal findings in $87 \%$ of cases, actual fistula or perforation visualized on CT chest confirming the diagnosis occurred in only one-third of cases. Other common findings include air in the mediastinum $(26 \%)$, pericardium or LA $(24 \%)$, pericardial or pleural effusion, and thickening or ulceration of the esophagus or LA. We thus propose a simple abbreviation, AEF-Tests, to recall the spectrum of major abnormalities seen on CT chest: Air (mediastinum or LA), Effusion (pleural or pericardial), Fistula or perforation, Thickening (esophagus/LA) and repeat Testing (Table 3 ).

Contrast, either intravenous, oral or both, was frequently used when conducting CT chest $(90 \%)$. While contrast may not be necessary to detect air in the LA, it should be recommended in the assessment of such patients unless contraindicated (e.g., known contrast allergy or severe renal impairment).

\section{Normal or non-specific initial CT Chest}


Fourteen patients $(13 \%)$ demonstrated normal or non-specific initial CT chest findings. Of note, the median time from AF ablation to initial CT chest in these patients was 14 days with a wide range (3-28 days). This suggests that the time course of AEF development is heterogeneous, and that performing CT chest early does not exclude progression to AEF. In one such case, an esophageal ulcer identified on CT chest 10 days post-procedure was followed judiciously with regular CT scans before finally developing into a sinus tract extending into the mediastinum 3 weeks after initial CT chest. ${ }^{17}$ This is unsurprising given that cases of AEF have presented up to 60 days following AF ablation. ${ }^{18,19}$ Interestingly, the main presenting symptoms in patients with normal initial CT chest were fever and chest pain. This differs from the wider presentation of AEF previously reported, whereby focal neurological symptoms are more common. ${ }^{11}$ The differing presentation appears consistent with the earlier disease stage in which AEF may not have fully developed and thus air emboli and subsequent neurological deficit had yet to occur. Of note, blood cultures were positive for streptococcus and usually grew multiple other bacterial species even when conducted around the time of the initial CT chest. While this is susceptible to reporting bias, the uniform positive blood cultures in the entire study cohort is certainly suggestive that it may be more sensitive in the earlier stages of AEF even compared with CT chest. Furthermore, in one patient, inflammatory markers were still unremarkable while blood cultures were positive, ${ }^{16}$ indicating that some patients may not mount an inflammatory response even when bacteremic. We suggest that blood cultures are crucial in the early assessment of suspected $\mathrm{AEF}$, and where multiple or gastrointestinal bacteriae are grown, close monitoring and repeat cardiac imaging should be considered.

For repeat CT chest imaging, most published cases describe abnormalities on repeat scan consistent with the major findings described above. The median time for repeat scan was 6 days although ranged from 4 to 22 days. Thus, a repeat scan at 1 week in patients with 
normal initial CT chest appears feasible, although it should be performed earlier and prompt action taken in patients with ongoing or worsening symptoms.

\section{Bedside, Blood and Biochemical Tests}

Although CT chest remains the most appropriate test to anatomically confirm AEF, some bedside, blood and biochemical investigations can help corroborate findings. Blood cultures are consistently positive for bacterial growth, in particular for streptococcus species and multiple organisms even in patients with normal CT chest. Thus, positive blood culture mandates exclusion of AEF with prompt further testing even if initial CT chest is normal. Inflammatory markers were generally elevated in most cases where reported. However, WCC was normal in about one-quarter of patients, and where increased, levels varied from slight to significant elevation. CRP were usually raised, which could reflect an inflammatory response to the ablation procedure (which usually peaks at 3 days and may be elevated up to 1 week post-procedure), or ongoing sepsis. ${ }^{20}$ A CRP $>100 \mathrm{mg} / \mathrm{dL}$ should raise clinical suspicion for possible AEF in the absence of other reasons for elevation. ECG was normal in about $40 \%$ of reported cases, with ST-segment elevation being the most common abnormality. While it is still important to exclude coronary artery stenosis, recent AF ablation warrants consideration of AEF.

\section{Other Radiological Modalities}

In relation to other radiological modalities, the most salient abnormality reported on CT or MRI head was diffuse air emboli and related ischemia. Such findings are almost pathognomonic of $\mathrm{AEF}^{21}$ and should alert clinicians towards prompt further investigation and management. ${ }^{22}$ However, unlike CT chest, about one-half of CT head scans can be normal even in the context of neurological symptoms. While MRI head appears to show more abnormalities compared with CT head, the far fewer scans performed, increased cost and 
often reduced accessibility limits the applicability of such findings. Echocardiography was infrequently performed and was usually indicated to exclude valvular pathology secondary to infective endocarditis or assess wall motion in the setting of ST-segment changes on ECG. It has a low yield for AEF, although findings such as pericardial effusion or thrombus in the LA should alert the clinician towards a diagnosis of AEF. Esophagram can be useful in confirming AEF with a distinct finding of esophageal contrast extravasation present in most cases (13/15). Unfortunately, both normal esophagrams were reported in patients with normal initial CT chest scans and thus its role in adjunction to a normal CT chest appears limited. Chest X-ray was normal in most patients (7/13) and its clinical utility in the assessment of AEF appears limited.

Imaging modalities that involve air insufflation pose a risk of potentiating air emboli through the fistulous tract. Several cases of subsequent widespread cerebral emboli and ischemia have been reported following $\mathrm{TEE}^{9,13}$ or upper gastrointestinal endoscopy ${ }^{23,24}$ and the use of such modalities should be avoided in suspected AEF.

\section{Study Limitations}

There are several limitations to our analysis that should be considered. First, the diagnostic accuracy of each imaging, bedside and biochemistry test is limited by reporting bias, where case reports and series may not report pertinent negative findings. Second, publication bias also influences interpretation of these results given that the positive predictive value of any given test cannot be accurately gauged through only published cases. Third, certain case reports were excluded due to lack of specific data on the investigations performed and their related findings (Table S1 in the Data Supplement). Finally, the subset of 14 patients with normal or non-specific initial CT chest findings represent a clinically pertinent cohort. Due to the limited data reported in certain original case reports and series, this cohort remains to be 
fully characterized and future detailed reports regarding this patient subset are crucial in understanding the progression of AEF.

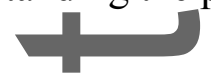

\section{Clinical Application}

$\mathrm{AEF}$ is a potentially lethal complication of AF ablation. In the assessment of suspected AEF, key investigations that should be performed include CT chest (with contrast), blood cultures, inflammatory markers and CT/MRI head in the presence of neurological symptoms. Current data mandate further assessment and close monitoring in patients with positive blood cultures for streptococcus, gastrointestinal bacteriae or multiple bacterial species even if initial CT chest is nermal. These patients are important to suspect AEF early as they usually do not present with neurological deficit yet, which in itself is a poor prognostic marker. ${ }^{11}$ An esophagram should also be considered where CT chest is equivocal. TEE and upper GI endoscopy are not recommended in the assessment of suspected AEF.

\section{CONCLUSION}

In the assessment of suspected AEF, only about one-third of cases have a clear visualization of fistula or perforation in CT chest. Other major findings include air in mediastinum, LA or wall of LA, pericardial or pleural effusions, and thickening of the esophagus or LA. More than 1 in 10 patients have a normal initial CT chest, although repeat scan at about 1 week after initial test confirmed the diagnosis in most cases. CT or MRI head show distinct findings of diffuse air emboli and ischemia. Blood culture is consistently positive even when initial CT chest is normal, and a significantly elevated CRP in the absence of other reasons should raise clinical suspicion. Although CT chest is the most appropriate radiological investigation for diagnosis, there are clear limitations in its yield and clinicians should be aware of the role of repeat testing and other relevant blood tests and imaging modalities. 


\section{REFERENCES

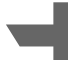

1. Chugh SS, Havmoeller R, Narayanan K, et al. Worldwide epidemiology of atrial fibrillation: a Global Burden of Disease 2010 Study. Circulation. 2014;129(8):837-47.

2. Wong CX, Brooks AG, Leong DP, Roberts-Thomson KC, Sanders P. The increasing burden of atrial fibrillation compared with heart failure and myocardial infarction: a 15-year study of all hospitalizations in Australia. Archives of internal medicine. 2012;172(9):739-41. 3. Kneeland PP, Fang MC. Trends in catheter ablation for atrial fibrillation in the United States. J Hosp Med. 2009;4(7):E1-5.

4. Wokhlu A, Monahan KH, Hodge DO, Asirvatham SJ, Friedman PA, Munger TM, Bradley DJ, Bluhm CM, Haroldson JM, Packer DL. Long-term quality of life after ablation of atrial fibrillation the impact of recurrence, symptom relief, and placebo effect. Journal of the American College of Cardiology. 2010;55(21):2308-16.

5. Cappato R, Calkins H, Chen SA, et al. Updated worldwide survey on the methods, efficacy, and safety of catheter ablation for human atrial fibrillation. Circulation Arrhythmia and electrophysiology. 2010;3(1):32-8.

6. Shah RU, Freeman JV, Shilane D, Wang PJ, Go AS, Hlatky MA. Procedural Complications, Rehospitalizations, and Repeat Procedures After Catheter Ablation for Atrial Fibrillation. Journal of the American College of Cardiology. 2012;59(2):143-9.

7. Deshmukh A, Patel NJ, Pant S, et al. In-hospital complications associated with catheter ablation of atrial fibrillation in the United States between 2000 and 2010: analysis of 93801 procedures. Circulation. 2013;128(19):2104-12. 
8. Cappato R, Calkins H, Chen SA, Davies W, Iesaka Y, Kalman J, Kim YH, Klein G, Natale A, Packer D, Skanes A. Prevalence and causes of fatal outcome in catheter ablation of atrial fibrillation. Journal of the American College of Cardiology. 2009;53(19):1798-803. 9. Pappone C, Oral H, Santinelli V, Vicedomini G, Lang CC, Manguso F, Torracca L, Benussi S,Alfieri O, Hong R. Atrio-esophageal fistula as a complication of percutaneous transcatheter ablation of atrial fibrillation. Circulation. 2004;109(22):2724-6.

10. Kapur S, Barbhaiya C, Deneke T, Michaud GF. Esophageal Injury and Atrioesophageal Fistula Caused by Ablation for Atrial Fibrillation. Circulation. $2017 ; 136(13): 1247-55$.

11. Han HC, Ha FJ, Sanders P, Spencer R, Teh AW, O'Donnell D, Farouque O, Lim HS. Atrio-esophageal fistula: clinical presentation, procedural characteristics, diagnostic investigations and treatment outcomes. Circulation Arrhythmia and electrophysiology. $2017 ; 10(11)$

12. Stockigt F, Schrickel JW, Andrie R, Lickfett L. Atrioesophageal fistula after cryoballoon pulmonary vein isolation. Journal of cardiovascular electrophysiology. 2012;23(11):1254-7.

13. O'Kane D, Pusalkar A, Topping W, Spooner O, Roantree E. An avoidable cause of cardioembolic stroke. Acute Medicine. 2013;13(3):126-8.

14. Kawasaki R, Gauri A, Elmouchi D, Duggal M, Bhan A. Atrioesophageal fistula complicating cryoballoon pulmonary vein isolation for paroxysmal atrial fibrillation. Journal of cardiovascular electrophysiology. 2014;25(7):787-92.

15. Gallo de Moraes A, Patel PA, Mahal E, Kramer CL, Diaz Soto JC, Moua T. Acute fever and seizure in a patient with recent atrial fibrillation ablation. Heart \& lung : the journal of critical care. 2015;44(4):314-6. 
16. Siegel MO, Parenti DM, Simon GL. Atrial-esophageal fistula after atrial radiofrequency catheter ablation. Clinical infectious diseases : an official publication of the Infectious Diseases Society of America. 2010;51(1):73-6.

17. Gilcrease GW, Stein JB. A delayed case of fatal atrioesophageal fistula following radiofrequency ablation for atrial fibrillation. Journal of cardiovascular electrophysiology. 2010;21(6):708-11.

18. Wilson BD, Morshedzadeh JH. Atrioesophageal fistula and pneumocephalus after pulmonary vein isolation. European heart journal cardiovascular Imaging. 2015;16(7):819.

19. Kanth P, Fang J. Cerebral air embolism: a complication of a bleeding atrioesophageal fistula. Clinical Gastroenterology and Hepatology. 2012;10(3):A22.

20. Lim HS, Schultz C, Dang J, et al. Time course of inflammation, myocardial injury, and prothrombotic response after radiofrequency catheter ablation for atrial fibrillation. Circulation Arrhythmia and electrophysiology. 2014;7(1):83-9.

21. Koa-Wing M, Jamil-Copley S, Ariff B, Kojodjojo P, Lim P, Whinnett Z, Rajakulendran S, Malhotra P, Lefroy D, Peters N. Haemorrhagic cerebral air embolism from an atrio-oesophageal fistula following atrial fibrillation ablation. Perfusion. 2014:0267659114562102.

22. Zellerhoff S, Lenze F, Schulz R, Eckardt L. Fatal course of esophageal stenting of an atrioesophageal fistula after atrial fibrillation ablation. Heart rhythm : the official journal of the Heart Rhythm Society. 2011;8(4):624-6.

23. Dagres N, Kottkamp H, Piorkowski C, Doll N, Mohr F, Horlitz M, Kremastinos DT, Hindricks G. Rapid detection and successful treatment of esophageal perforation after radiofrequency ablation of atrial fibrillation: lessons from five cases. Journal of cardiovascular electrophysiology. 2006;17(11):1213-5. 
24. Zini A, Carpeggiani P, Pinelli G, Nichelli P. Brain air embolism secondary to atrialesophageal fistula. Arch Neurol. 2012;69(6):785.

25. Doll N, Borger MA, Fabricius A, Stephan S, Gummert J, Mohr FW, Hauss J, Kottkamp H, Hindricks G. Esophageal perforation during left atrial radiofrequency ablation: Is the risk too high? The Journal of Thoracic and Cardiovascular Surgery. 2003;125(4):83642.

26. Hirji SA, Haney JC, Welsby I, Lombard FW, Berry MF. Hyperbaric oxygen therapy for treatment of neurologic sequela after atrioesophageal fistula. The Annals of thoracic surgery. 2015;99(2):681-2.

27. Cazavet A, Muscari F, Marachet MA, Leobon B. Successful surgery for atrioesophageal fistula caused by transcatheter ablation of atrial fibrillation. $\mathrm{J}$ Thorac Cardiovase Surg. 2010;140(3):e43-5.

28. Shalaby A, Refaat M, Sebastien G, Zenati M. Conservative management of pericardial-esophageal fistula complicating robotic atrial fibrillation ablation. Heart rhythm : the official journal of the Heart Rhythm Society. 2011;8(6):905-8.

29. EsSandoh M, Otey AJ, Crestanello J, Keshishian J, Brady PG, Gerlach RM. CASE 92015: Anesthetic Management of a Patient With Esophago-Pericardial Fistula Complicating Atrial Fibrillation Radiofrequency Ablation. Journal of cardiothoracic and vascular anesthesia. 2015;29(5):1357-64.

30. Lempel JK, Jozwik B, Manfredi C, Shih AC. Cerebral air embolism: a result of atrioesophageal fistula. American Journal of Neuroradiology. 2012;33(3):E40-E1.

31. French K, Garcia C, Wold J, Hoesch R, Ledyard H. Cerebral air emboli with atrialesophageal fistula following atrial fibrillation ablation a case report and review. The Neurohospitalist. 2011;1(3):128-32. 


\section{FIGURE LEGEND}

\section{Figure 1. Search Algorithm. \\ AEF, Atrio-esophageal fistula}

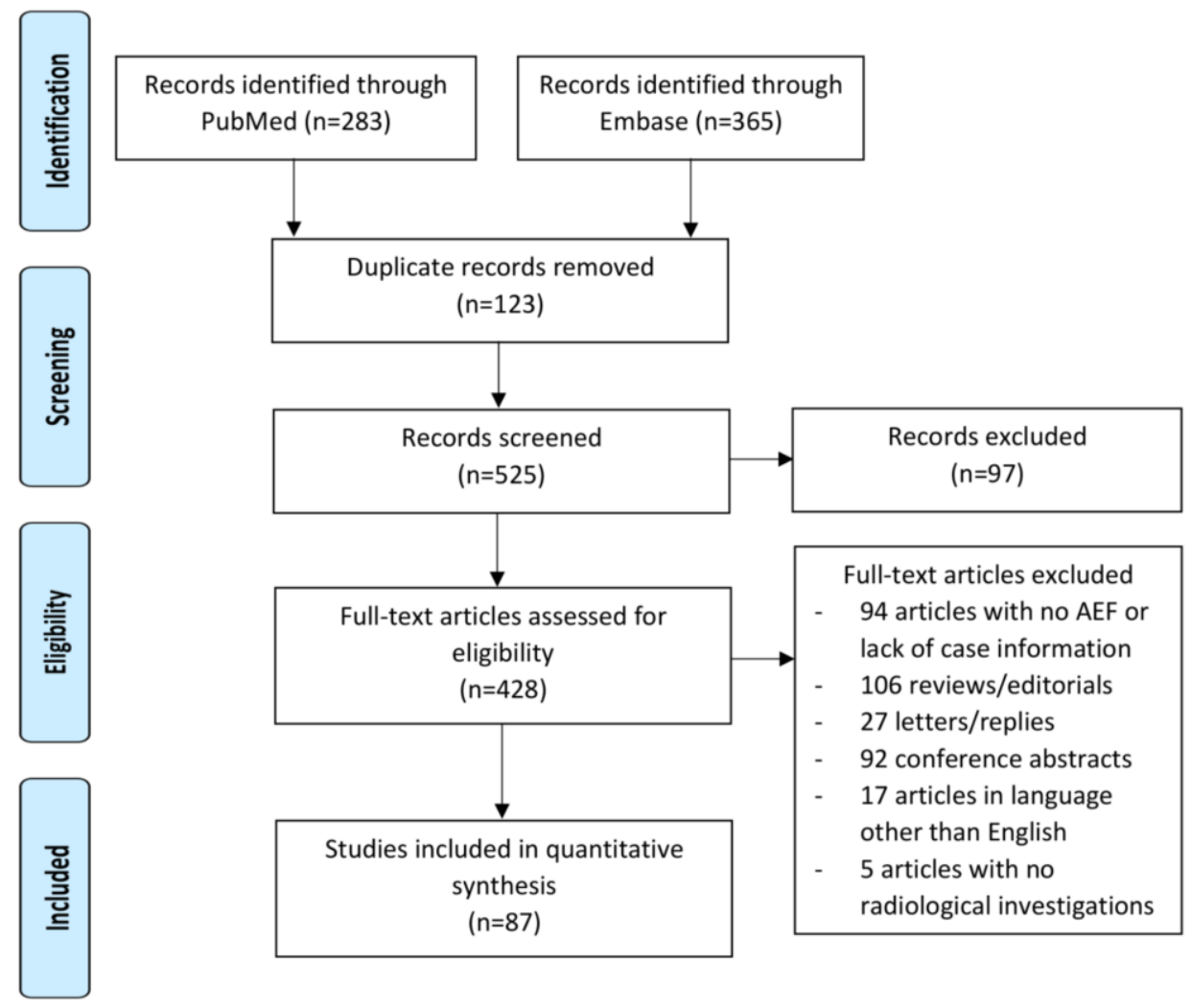

Figure 2. Frequency of investigations performed on initial evaluation of AEF and major finding.

AEF, Atrio-esophageal fistula; CT, Computed Tomography; MRI, Magnetic Resonance Imaging; TEE, Trans-esophageal echocardiography; TTE, Trans-thoracic echocardiography

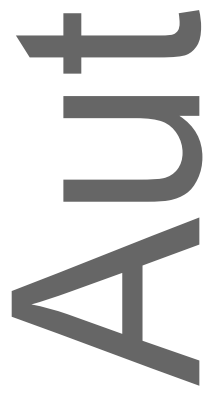




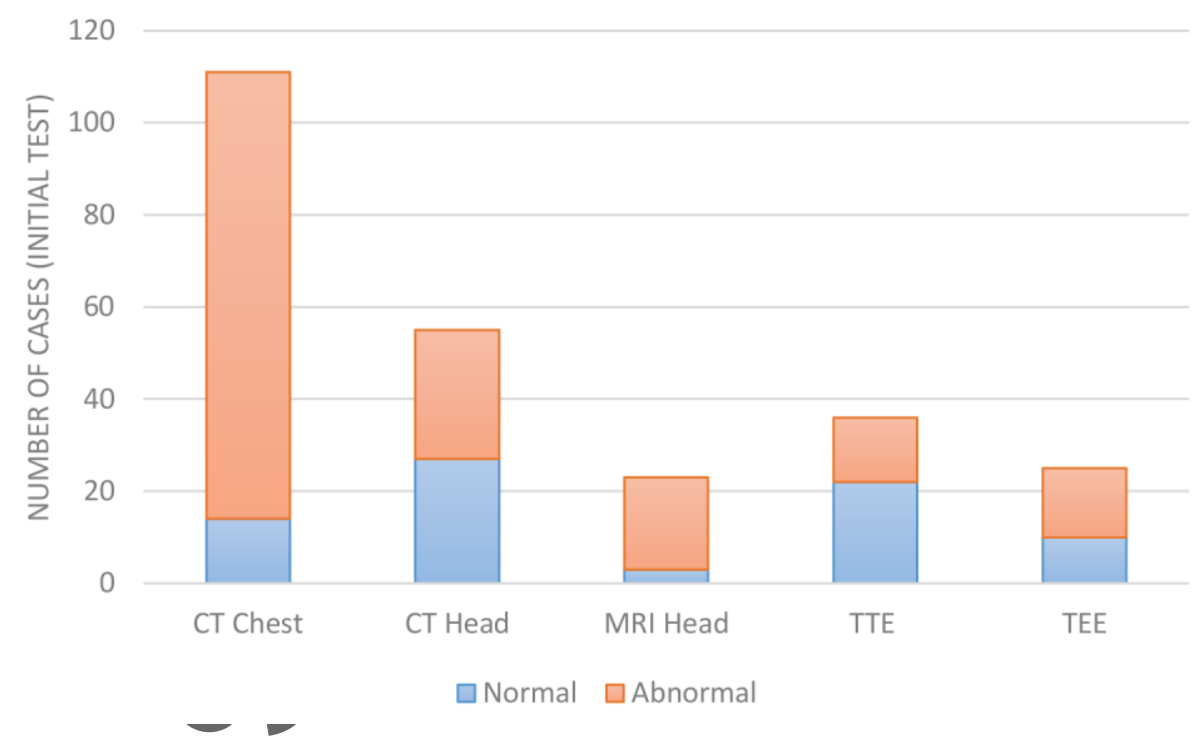

Figure 3. Primary diagnostic modality for AEF.

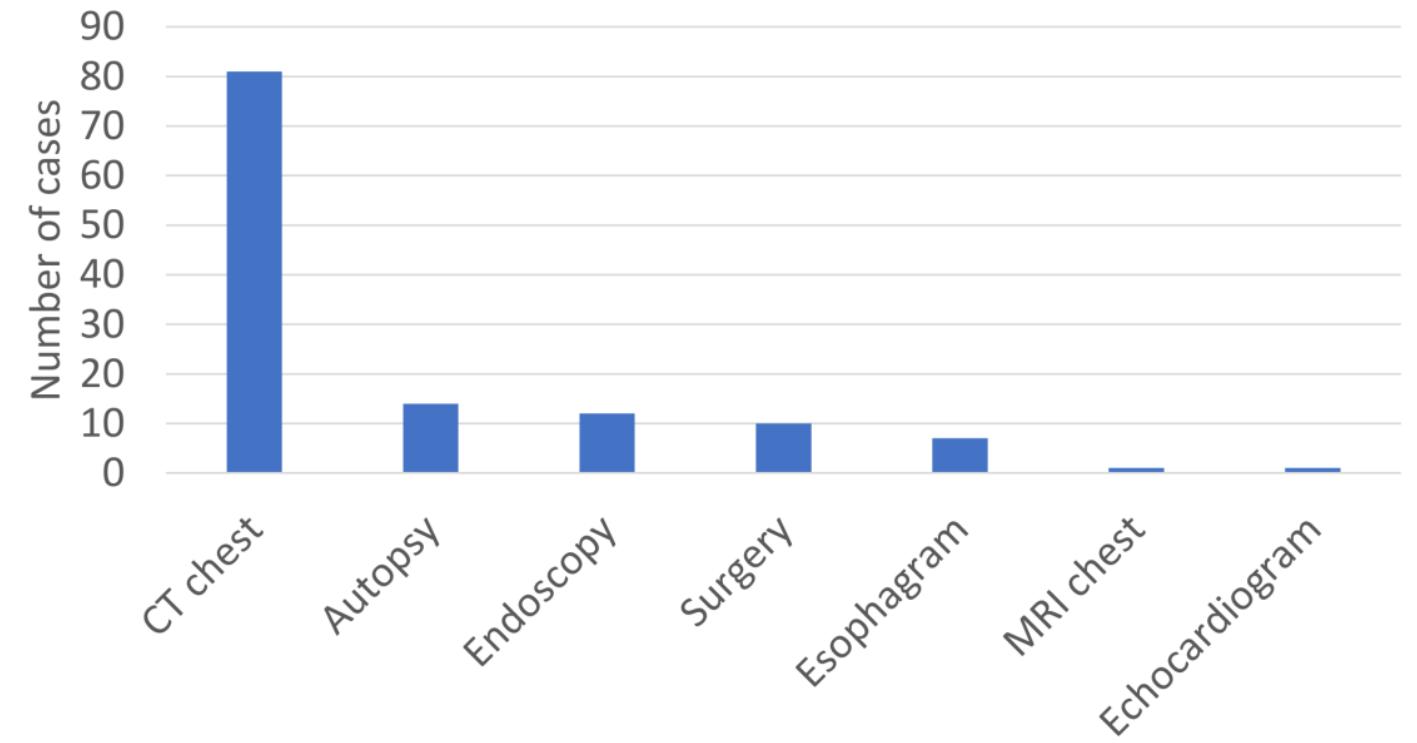

Figure 4. Findings on initial CT chest in relation to time performed (A) and specific abnormal findings (B).

CT, Computed Tomography; LA, Left atrium

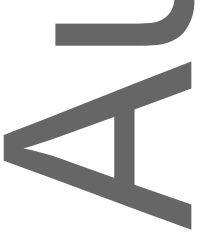




\section{CT Chest - Abnormal Findings}

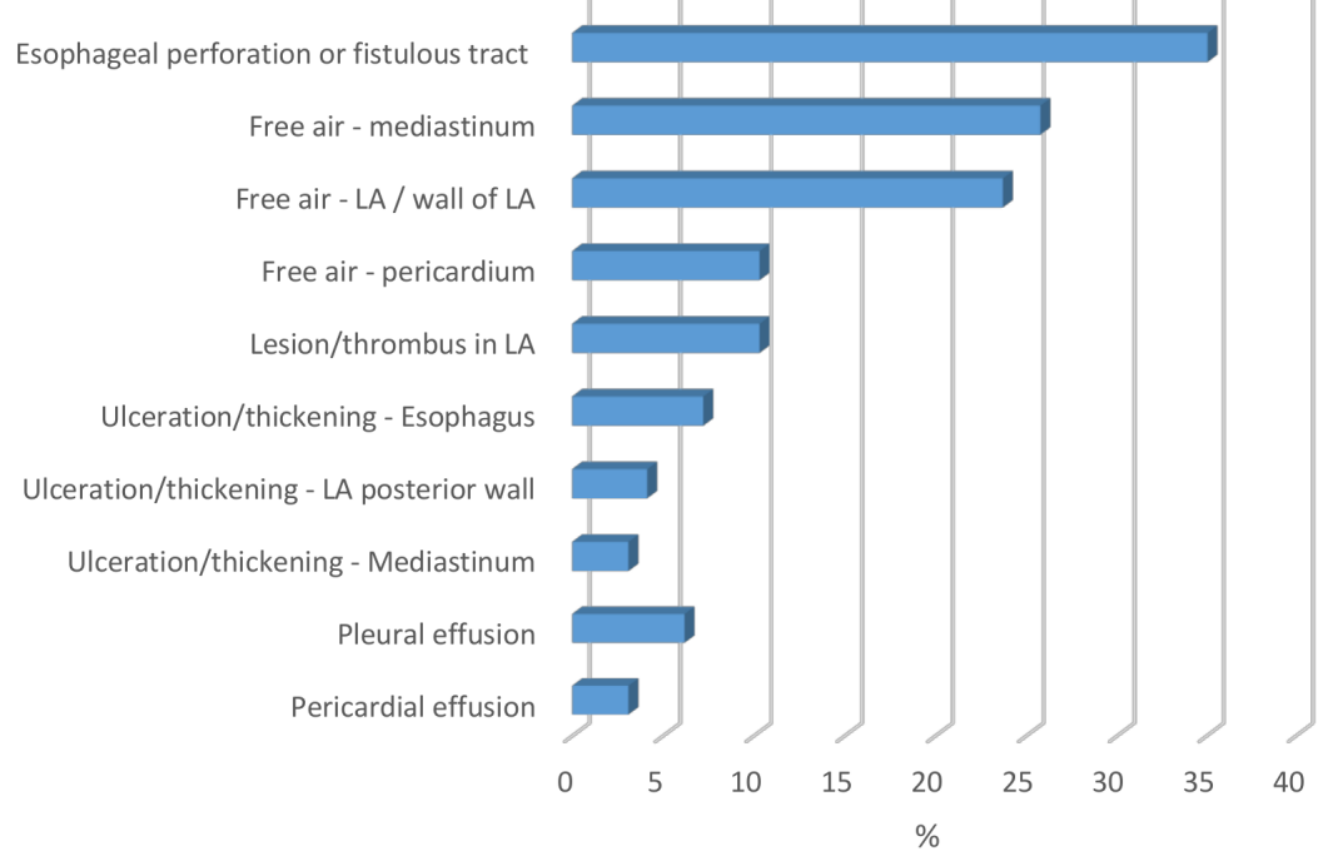

Figure 5. Findings on CT chest.

(A) Pneumomediastinum in 59yo male with fever and neurologic symptoms POD 12. (B) Air in posterior LA in 46yo male with fever, confusion and right-sided weakness post-op day 7. (C) Axial and (D) sagittal view of pneumomediastinum and LA air in 35yo male with fever, chest pain and vomiting POD 38. (E) Pneumopericardium and (F) pneumomediastinum in 44yo male with chest discomfort, nausea, vomiting and dyspnea 1 month post-op. (G) Pneumoperieardium (white arrow) and hemopericardium (black arrow) in 60yo male with pleuritic chest pain, fever and dyspnea 2 weeks post-op. (H) LA air in 63yo male with fever, malaise and left arm weakness 5 weeks post-op.

LA, Left atrium; POD, Post-operative day

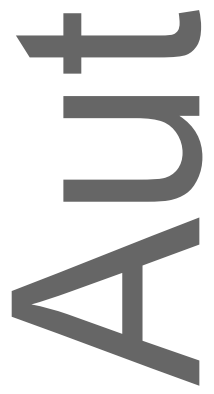



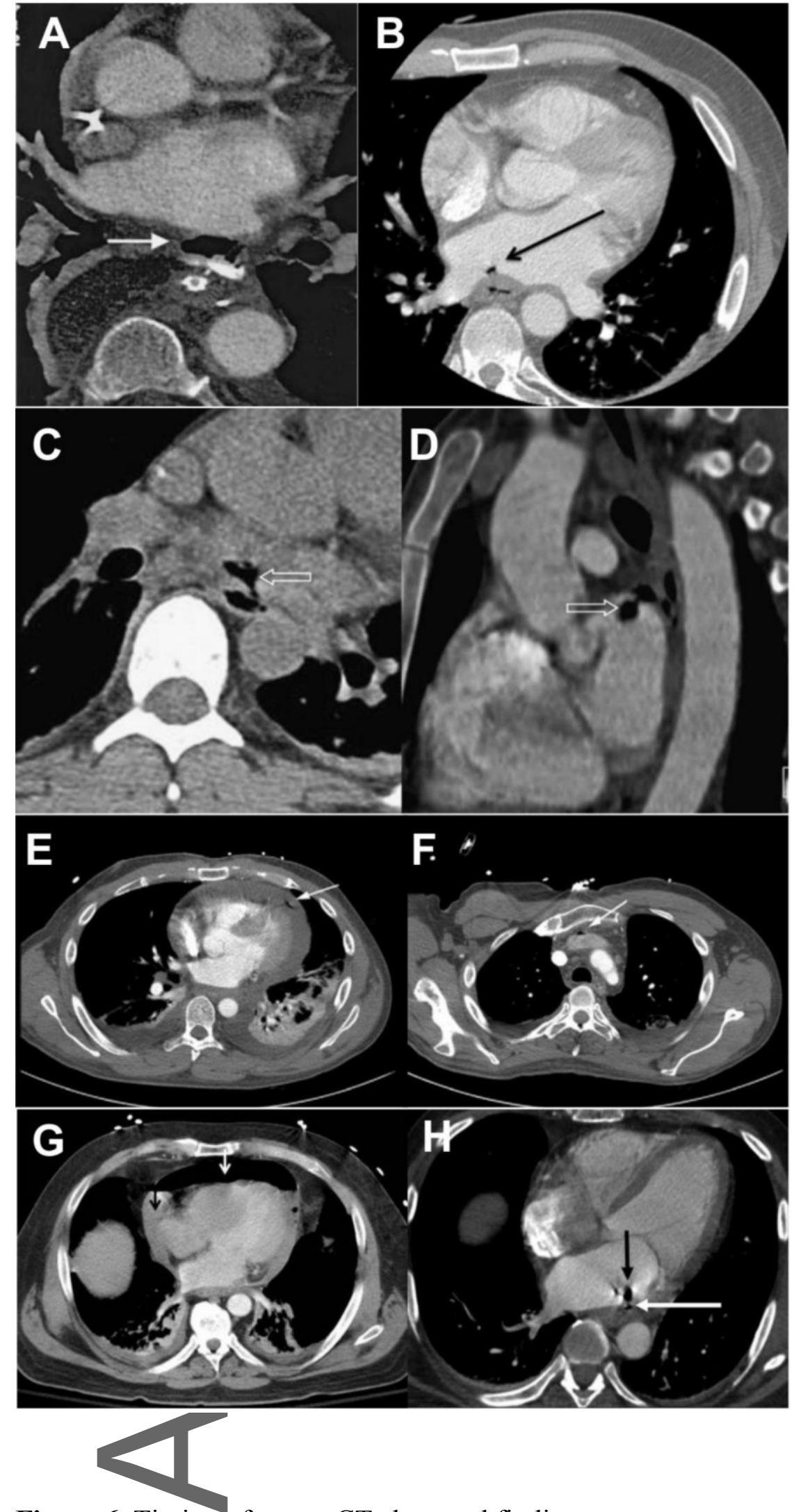

Figure 6. Timing of repeat $\mathrm{CT}$ chest and findings.

Number correlates to case no. in Table 2.

LA, Left atrium; NR, Not recorded; PV, Pulmonary vein

This article is protected by copyright. All rights reserved. 


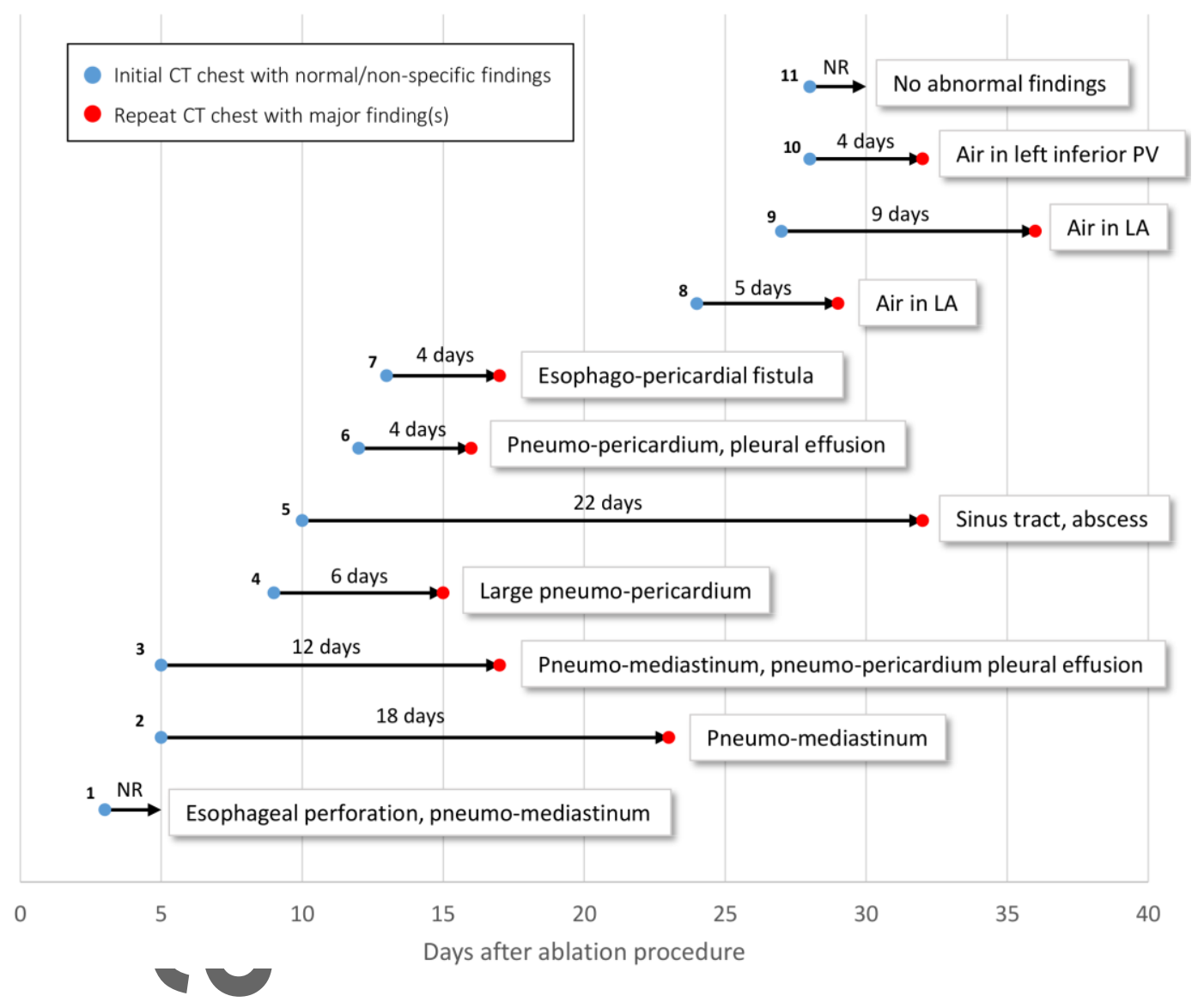

Figure 7.Findings on non-contrast CT head.

(A) Multiple foci of air in 63yo male with fever, malaise and left arm weakness 5 weeks post-op. (B) Locules of air with (C) extensive infarction and hemorrhage in 45yo male presenting with collapse and coffee-ground vomiting 2 weeks post-op. (D) Extensive, multifocal intravascular pneumocephalus within cortical vessels, dural venous sinuses, subarachnoid space and cerebral parenchyma in 69yo male with left-sided weakness and right gaze preference at POD 50.

POD, Post-operative day

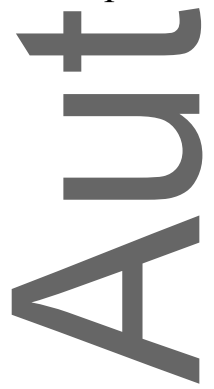



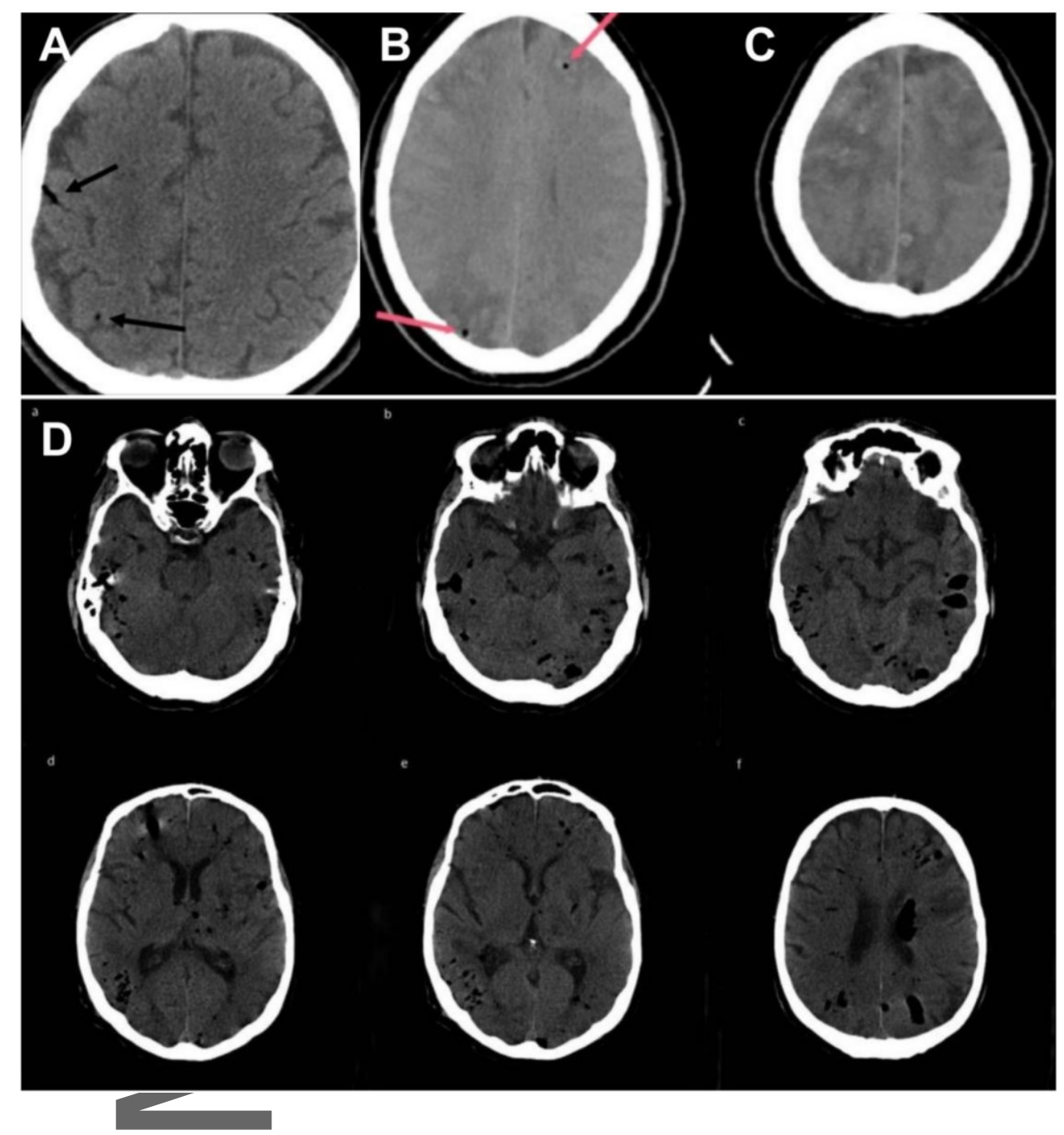

\section{Footnotes}

Figure 5A. Reprinted from The Journal of Thoracic and Cardiovascular Surgery. Doll et al. 2003;125(4):836-42 with permission from Elsevier. ${ }^{25}$

Figure 5B. Reprinted from The Annals of thoracic surgery. Hirji et al. 2015;99(2):681-2 with permission from Elsevier. ${ }^{26}$

Figure 5C and 5D.Reprinted from The Journal of Thoracic and Cardiovascular Surgery. Cazavet et al. 2010:140(3):e43-45 with permission from Elsevier. ${ }^{27}$

Figure 5E and 5F. Reprinted from Heart Rhythm. Shalaby et al. 2011;8(6):905-8 with permission from Elsevier. 28

Figure 5G. Reprinted from Journal of cardiothoracic and vascular anesthesia. Essandoh et al. 2015;29(5):1357-64 with permission from Elsevier. ${ }^{29}$

Figure 5H. Reprinted from American Journal of Neuroradiology. Lempel et al. 2012;33(3):E40-E1 with permission from American Society of Neuroradiology. ${ }^{30}$ 
Figure 7A. Reprinted from American Journal of Neuroradiology. Lempel et al. 2012;33(3):E40-E1 with permission from American Society of Neuroradiology. ${ }^{30}$

Figure 7B and 7C. Reprinted from Perfusion. Koa-Wing et al. 2014 with permission from SAGE Publishing.

Figure 7D. Reprinted from The Neurohospitalist. French et al. 2011;1(3):128-32 with permission from SAGE Publishing. ${ }^{3}$

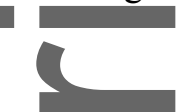

\section{Table 1. Patient baseline characteristics}

\begin{tabular}{lc}
\hline Patient demographics & $\mathrm{N}=126(\%)$ \\
\hline Age, median years (range) & $59(27-85)$ \\
Gender, Male & $1(1)$ \\
NS duration & $37(29)$ \\
Paroxysmal & $36(29)$ \\
Pblation Procedure & $53(42)$ \\
PRFA & \\
Surgical & \\
Cryoballoon & \\
\end{tabular}

AF, Atrial fibrillation; CT, Computed tomography; HIFU, High intensity focused ultrasound; NS, Not specified; PRFA, Percutaneous radiofrequency ablation 


\section{Table 2. Summary of patients who underwent repeated CT chest following}

normal or non-specific findings on initial

\begin{tabular}{|c|c|c|c|c|c|}
\hline No. & $\begin{array}{c}\text { Author } \\
\text { (year) }\end{array}$ & $\begin{array}{l}\text { Initial CT } \\
\text { Chest - } \\
\text { Post- } \\
\text { operative } \\
\text { day } \\
\text { performed }\end{array}$ & $\begin{array}{l}\text { Repeated } \\
\text { CT chest - } \\
\text { Post- } \\
\text { operative } \\
\text { day } \\
\text { performed }\end{array}$ & $\begin{array}{l}\text { Reason for } \\
\text { repeat } \\
\text { investigation }\end{array}$ & $\begin{array}{c}\text { Findings of repeated CT } \\
\text { chest }\end{array}$ \\
\hline 1 & $\begin{array}{c}\text { Kawasaki } \begin{array}{c}\text { Dysphagia, } \\
\text { rigors }\end{array} \\
\text { et al. (2014) }\end{array}$ & Day 17 & Not recorded & $\begin{array}{c}\text { Strong clinical } \\
\text { suspicion based } \\
\text { on patient's initial } \\
\text { clinical } \\
\text { presentation }\end{array}$ & $\begin{array}{l}\text { Contained perforation of the } \\
\text { mid-distal esophagus with air } \\
\text { seen in anterior aspect of } \\
\text { posterior mediastinum } \\
\text { adjacent to esophagus but } \\
\text { without fistulous } \\
\text { communication }\end{array}$ \\
\hline 2 & $\begin{array}{l}\text { Gitenay et } \quad \mathrm{CP} \text {, dysphagia } \\
\text { al. }(2016)\end{array}$ & Day 5 & Day 23 & $\begin{array}{l}\text { Represented with } \\
\text { fever and severe } \\
\text { headaches }\end{array}$ & Pneumomediastinum \\
\hline 3 & $\begin{array}{cc}\text { Keshishian } & \text { Nausea, } \\
\text { et al. }(2012) & \begin{array}{c}\text { epigastric pain } \\
\text { radiating to } \\
\text { back }\end{array}\end{array}$ & Day 5 & Day 17 & $\begin{array}{l}\text { Represented with } \\
\text { acute-onset CP } \\
\text { and fever }\end{array}$ & $\begin{array}{c}\text { Pneumomediastinum, } \\
\text { pneumopericardium with } \\
\text { moderate pericardial effusion }\end{array}$ \\
\hline 4 & $\begin{array}{lc}\text { Grubina et } & \text { Recurrent } \\
\text { al. }(2010) & \text { pleuritic CP }\end{array}$ & Day 9 & Day 15 & $\begin{array}{l}\text { Worsening } \\
\text { pleuritic CP }\end{array}$ & Large pneumopericardium \\
\hline
\end{tabular}

\begin{tabular}{|c|c|c|c|c|c|c|}
\hline 5 & $\begin{array}{l}\text { Gilcrease et } \\
\text { al. }(2010)\end{array}$ & $\begin{array}{l}\text { Dyspnea, } \\
\text { substernal CP } \\
\text { radiating to } \\
\text { back, fever }\end{array}$ & Day 10 & Day 32 & $\begin{array}{l}\text { Represented with } \\
\text { low grade fever }\end{array}$ & $\begin{array}{l}\text { Sinus tract extending from } \\
\text { esophageal ulcer into } \\
\text { mediastinum and pericardial } \\
\text { fat with possible small } \\
\text { abscess }\end{array}$ \\
\hline 6 & $\begin{array}{c}\text { Gunes et al. } \\
(2015) \\
\end{array}$ & $\begin{array}{l}\text { Dyspnoea, left- } \\
\text { sided CP } \\
\text { radiating to } \\
\text { lower left } \\
\text { scapula }\end{array}$ & Day 12 & Day 16 & $\begin{array}{l}\text { Represented with } \\
\text { persisting } \\
\text { dyspnea and left- } \\
\text { sided chest pain } \\
\text { and new-onset } \\
\text { fever } \\
\left(39^{\circ} \text { Celcius }\right)\end{array}$ & $\begin{array}{l}\text { Air in the pericardium } \\
\text { anterior to the esophagus and } \\
\text { purulent pericardial effusion }\end{array}$ \\
\hline 7 & $\begin{array}{r}\text { Eitel e } \\
(201\end{array}$ & $\begin{array}{l}\text { Dysphagia, } \\
\text { etrosternal CP }\end{array}$ & Day 13 & Day 17 & $\begin{array}{c}\text { Sudden onset of } \\
\text { violent persisting } \\
\text { pain after } \\
\text { drinking water }\end{array}$ & $\begin{array}{c}\text { Esophago-pericardial fistula } \\
\text { near the inferior left } \\
\text { pulmonary vein }\end{array}$ \\
\hline 8 & $\begin{array}{l}\text { Siegel et al. } \\
\text { (2010) }\end{array}$ & $\begin{array}{l}\text { Fever, chills, } \\
\text { near-syncope }\end{array}$ & Day $\sim 24$ & Day $\sim 29$ & $\begin{array}{l}\text { Onset of fever } \\
\left(39^{\circ} \text { Celcius }\right) \text { and } \\
\text { right-sided } \\
\text { hemiparesis }\end{array}$ & $\begin{array}{l}\text { Small 8mm dependent air } \\
\text { density in left atrium but } \\
\text { normal-appearing esophagus }\end{array}$ \\
\hline
\end{tabular}




\begin{tabular}{ccccccc}
\hline 9 & $\begin{array}{c}\text { Khandar et } \\
\text { al. (2010) }\end{array}$ & High fever & Day 27 & Day $\sim 36$ & $\begin{array}{c}\text { Onset of transient } \\
\text { left hemiparesis } \\
\text { and expressive } \\
\text { aphasia }\end{array}$ & $\begin{array}{c}\text { Dependent air in the region } \\
\text { of the left atrium adjacent to } \\
\text { esophagus }\end{array}$ \\
\hline 10 & $\begin{array}{c}\text { Stockigtet } \\
\text { al. (2012) }\end{array}$ & $\begin{array}{c}\text { Fever, chills, } \\
\text { cough }\end{array}$ & Day $\sim 28$ & Day $\sim 32$ & $\begin{array}{c}\text { Developed } \\
\text { massive bi- } \\
\text { hemispheric } \\
\text { stroke }\end{array}$ & $\begin{array}{c}\text { Air trapped in the left inferior } \\
\text { pulmonary vein wall next to } \\
\text { the esophagus }\end{array}$ \\
\hline 11 & $\begin{array}{c}\text { Gallo De } \\
\text { Moraes et } \\
\text { al. (2015) }\end{array}$ & Seizure & Day $\sim 28$ & Not recorded & $\begin{array}{c}\text { Developed } \\
\text { convulsive status } \\
\text { epilepticus and } \\
\text { hematemesis }\end{array}$ & $\begin{array}{c}\text { No abnormal findings } \\
\text { detected }\end{array}$ \\
\hline
\end{tabular}

All patients initial CT chest demonstrated no significant abnormal finding

$C P$, Chest pain

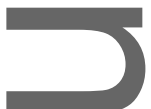

Table 3. Spectrum of Abnormalities on Diagnostic Tests for AEF "AEF-Tests"

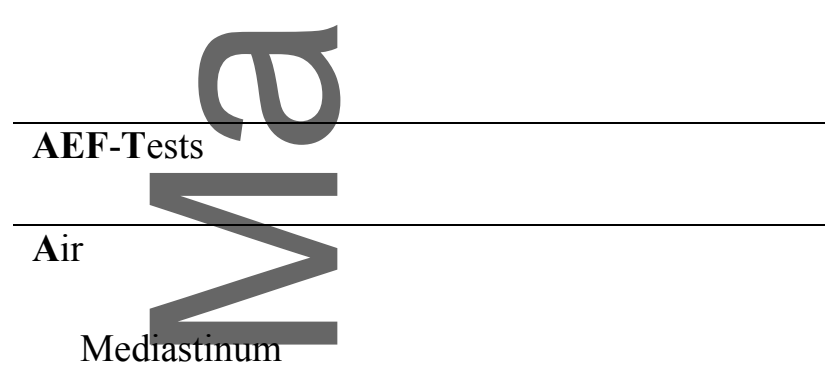

\section{LA or pericardium}

Effusion

Pleural

Pericardium

Fistula/Perforation

Thickening

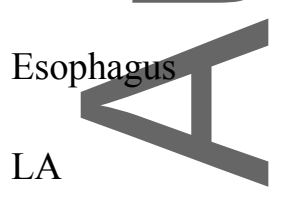

Testing (Repeat) 
Blood culture also consistently positive for bacterial growth.

$C T$ and MRI head can show distinct findings of diffuse air emboli and related ischemia.

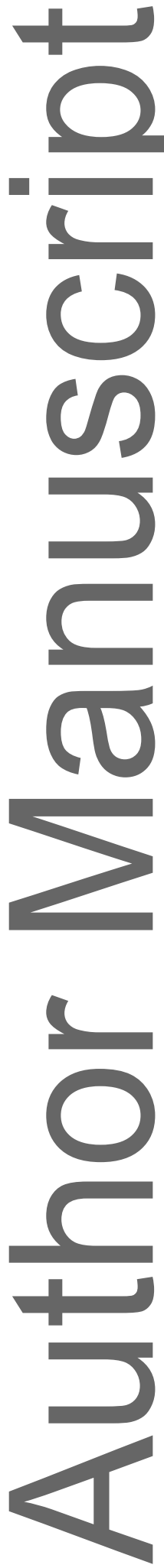

This article is protected by copyright. All rights reserved. 


\section{University Library}

\section{- M M N E R VA A gateway to Melbourne's research publications}

Minerva Access is the Institutional Repository of The University of Melbourne

Author/s:

Ha, FJ;Han, H-C;Sanders, P;Teh, AW;O'Donnell, D;Farouque, O;Lim, HS

Title:

Challenges and limitations in the diagnosis of atrioesophageal fistula

Date:

2018-06-01

Citation:

Ha, F. J., Han, H. -C., Sanders, P., Teh, A. W., O'Donnell, D., Farouque, O. \& Lim, H. S.

(2018). Challenges and limitations in the diagnosis of atrioesophageal fistula. JOURNAL OF CARDIOVASCULAR ELECTROPHYSIOLOGY, 29 (6), pp.861-871. https://doi.org/10.1111/ jce.13494.

Persistent Link:

http://hdl.handle.net/11343/283794 